\title{
Treating open lower limb fractures successfully; thoughts and current practice on therapy and centralization in The Netherlands
}

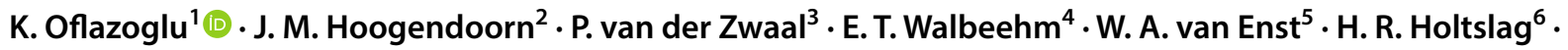 \\ D. Hofstee ${ }^{7} \cdot$ P. Plantinga ${ }^{8} \cdot$ M. Elzinga ${ }^{9} \cdot$ H. Rakhorst ${ }^{10}$
}

Received: 23 July 2017 / Accepted: 4 November 2017 / Published online: 27 November 2017

(c) The Author(s) 2017. This article is an open access publication

\begin{abstract}
Introduction The British Orthopedic Association (BOA) and British Association of Plastic, Reconstructive and Aesthetic Surgeons (BAPRAS) updated the evidence-based guidelines for the treatment and care of open lower limb fractures (BOAST 4). Following this, a Dutch version has been developed. The main points are multidisciplinary care, planning, and treatment of these injuries. Early osteosynthesis (within 7-14 days) combined with soft-tissue coverage results in more efficient care and less complications.

Aim To study the variation in treatment and thoughts among trauma, orthopedic, and plastic surgeons.

Materials and methods In this cross-sectional study 94 surgeons (57 trauma, 23 plastic, and 14 orthopedic surgeons) working at 46 centers completed an online questionnaire, consisting of 5 demographic, 14 hospital-related, 8 BOAST 4-related, and 2 centralization-related questions.

Results There was a strong agreement among surgeons about the best moment for multidisciplinary consultation, which was before initial debridement, while in practice, this often does not occur. All surgeons agreed that the initial debridement should be performed immediately by any surgeon, but not solely by trainees. Plastic surgeons responded that the definitive stabilization and wound cover should not exceed 7 days, while half of the trauma and orthopedic surgeons agreed that it should not exceed 14 days. Finally, most surgeons agreed that Gustilo 3 fractures should be centralized. However, there was disagreement on the need for centralization of Gustilo 2 fractures.

Discussion Surgeons agree on better and earlier multidisciplinary treatment of open lower limb fractures and the centralization of Gustilo 3 fractures.
\end{abstract}

Keywords Open lower limb fractures · Multidisciplinary treatment $\cdot$ National survey

\section{Introduction}

Severe open lower limb fractures typically occur in young males as a result of a motorcycle accident [1]. These typical injuries are complex and patients often present with multiple injuries. As a result, prolonged treatment, hospital stay, and rehabilitation are characteristic in these people in the middle of careers and developing family lives. Although these injuries have a low incidence, all these factors result in high impacts on the patient life and psychology [2]. Treatment should, therefore, focus on decreasing treatment duration and postoperative complications to a minimum.

\section{K. Oflazoglu \\ k.oflazoglu@gmail.com}

Extended author information available on the last page of the article
Medical infrastructure concerning these traumas has been set up in several countries. They aim to get severely injured patients appropriate care within the system, without transfer delay [3-7]. In 2009, the British Orthopedic Association (BOA) and British Association of Plastic, Reconstructive and Aesthetic Surgeons (BAPRAS) updated the evidence-based standards of care for the management of severe open lower leg fractures (BOAST 4) [8]. Early transfer and extensive teamwork and expertise between surgical and non-surgical specialties ensure a good clinical outcome. Several studies reported successful results of major trauma centres (MTC) in the United Kingdom following these standards. A decrease in treatment time, fewer required surgeries per patient, and a higher successful limb reconstruction rate have led to a decrease in deep infection rate [9-11]. 
A similar guideline is being developed in The Netherlands following the BOAST 4 . With an estimated 580 new cases of open lower limb fractures in The Netherlands, almost half is classified as a Gustilo 3 fracture, based on the incidence of the UK $[12,13]$. The Netherlands is a small country of $150 \times 300 \mathrm{~km}$ and is densely populated with 17 million people and 134 hospitals with 91 emergency units. Infrastructure is so that in $201499.8 \%$ of the population lived within a 45-min ambulance ride from an emergency unit [14]. The guideline calls for early multidisciplinary care, planning, and treatment for these injuries. This would result in more combined approaches of osteosynthesis and soft-tissue coverage, improving outcome and reducing complications [15].

The aim of the present study was to study the current practice and therapy of these injuries in The Netherlands, with respect to the timing of multidisciplinary consultation (MDC), timing of debridement, target period for softtissue coverage, and centralizing these injuries.

\section{Materials and methods}

\section{Study design}

In this cross-sectional study, departments of orthopedic surgery, trauma surgery, and plastic surgery of 70 different hospital units in The Netherlands were contacted by e-mail between November 2015 and June 2016 to invite the surgeons to participate in this study.

All participants were asked to complete an online questionnaire to collect the following data: five hospital related (e.g., type of hospital, other specialists working at the hospital, how many colleagues in a partnership), 14 current treatment related (e.g., how many treated open tibial fractures per year, who participates in a multidisciplinary team when is the treatment plan discussed, time of definitive soft-tissue coverage), 8 BOAST 4 guideline-based questions, and 2 questions about centralizing these injuries.

Data were collected using SurveyMonkey (https://www. surveymonkey.com), an online data collection program. Most questions were on Gustilo 2 or higher, since Gustilo 2 fractures are frequently classified as Gustilo 3 after initial debridement [13].

\section{Statistical analysis}

Results will be stated as frequencies and percentages. The difference in opinion about centralization of Gustilo 2 and Gustilo 3 fractures is analysed using the Wilcoxon matched-pairs signed-ranks test.

\section{Results}

\section{Surgeon characteristics}

Ninety-four surgeons returned the questionnaire: 57 trauma surgeons, 23 plastic surgeons, and 14 orthopedic surgeons, working at 46 different hospitals, a response rate of $60 \%$ for trauma surgery units, $40 \%$ of plastic surgery units, and $11 \%$ of orthopedic surgery units. Most surgeons (39\%) worked in a top clinical hospital and in most cases (44\%) a level I emergency department (Table 1). Four orthopedic surgery departments replied that open tibial fractures were not treated at their departments, and were excluded.

\section{Hospital characteristics}

The most noticeable results are described; see Table 2 in "Appendix" for all results. As mentioned, four hospitals replied that it did not treat or accept any eligible injuries, and these hospitals were excluded from the results. Most participants $(>70 \%)$ worked in a hospital with all team members of a multidisciplinary team hold practice. These specialties were defined as ER doctors, rehabilitation specialists, plastic surgeons with microsurgery facilities, trauma surgeons, and trauma-focused orthopedic surgeons.

Seventy-three percent of the surgeons responded that they treat less than ten patients with a severe open lower limb fracture annually, whereas $7.6 \%$ treat more than 20 cases per year. According to $73 \%$ of the surgeons, the best moment for MDC in case of a Gustilo $\geq 2$ fracture is prior to a first debridement. When asking for in which phase in their current practice this occurs, typically, MDC at the ER is not part of the standard procedures (Fig. 1).

Usually, the trauma or orthopedic surgeon has the lead after presentation of the patient at the Emergency Department (ED). This specialist can consult other specialties at his or her request. While most surgeons $(71 \%)$ believe that MDC should occur before first debridement, almost half of the trauma surgeons replied that not everyone is available for MDC at night.

Two-thirds of the hospitals had a defined specialized multidisciplinary team. The UK guideline calls choosing for debridement by a specialized team over debridement as soon as possible. When asking surgeons on their opinion on timing of debridement, in the middle of the night or the next day by special-interest surgeons, $54 \%$ of all surgeons choose time over team, where debridement in the middle of the night by an on-call colleague is preferred. Only $24 \%$ believe that it should be performed within $24 \mathrm{~h}$ by a multidisciplinary team of plastic and orthopedic of trauma surgeon working together (Fig. 2). 
Table 1 Characteristics of the surgeons who completed the questionnaire about the current practice and therapy in The Netherlands

\begin{tabular}{ll}
\hline Surgeon characteristics & $n=94$ \\
& $n(\%)$ \\
\hline Specialists & $57(61)$ \\
Trauma surgeon & $23(24)$ \\
Plastic surgeon & $14(15)$ \\
Orthopedic surgeon & \\
Hospital & $24(26)$ \\
Academic & $37(39)$ \\
Top clinical & $33(35)$ \\
Rural & \\
Emergency department & $41(44)$ \\
Level I & $33(35)$ \\
Level II & $20(21)$ \\
Level III & \\
\hline
\end{tabular}

The first debridement is usually performed by either the trauma or the orthopedic surgeon. In one-fifth of the cases, it is performed by the plastic surgeon.

According to $91 \%$ of respondents, negative pressure wound therapy is generally preferred not to be used longer than 2 weeks. Some surgeons specifically pointed out that this decision is multi-factorial and depends on issues such as size of the wound or logistical issues, e.g., availability theatre time for flap surgery.

Plastic surgeons keep 7 days as target period between time of injury and definitive osteosynthesis and soft-tissue cover. They prefer a combined approach instead of a staggered approach, where osteosynthesis and cover are separate procedures. More than $40 \%$ of the orthopedic and trauma surgeons have a longer target period of 14 days (Fig. 3).

Finally, only 54\% - mostly plastic surgeons - agreed that Gustilo 2 fractures should be centralized, while a significantly $(P<0.001)$ higher percentage of $79 \%$ of all surgeons agreed that Gustilo 3 fractures should be centralized (Fig. 4).

\section{Discussion}

The goal of this paper was to have a proper assessment of the variation in the current perspectives and management of open lower limb fractures in The Netherlands using a national survey among plastic, orthopedic, and trauma surgeons. The majority of the surgeons agreed that the best moment for MDC in case of a Gustilo $\geq 2$ fracture is prior to a first debridement. Half of the surgeons chose time over team, where debridement in the middle of the night by an on-call colleague is preferred. In one-fifth of the cases, it is performed by the plastic surgeon. More than $40 \%$ of the
Fig. 1 a Best moment for multidisciplinary consultation in case of a lower limb Gustilo 3 fracture. $\mathbf{b}$ In how many of the cases, multidisciplinary consultation takes place at the ER in case of a lower limb Gustilo 3 fracture

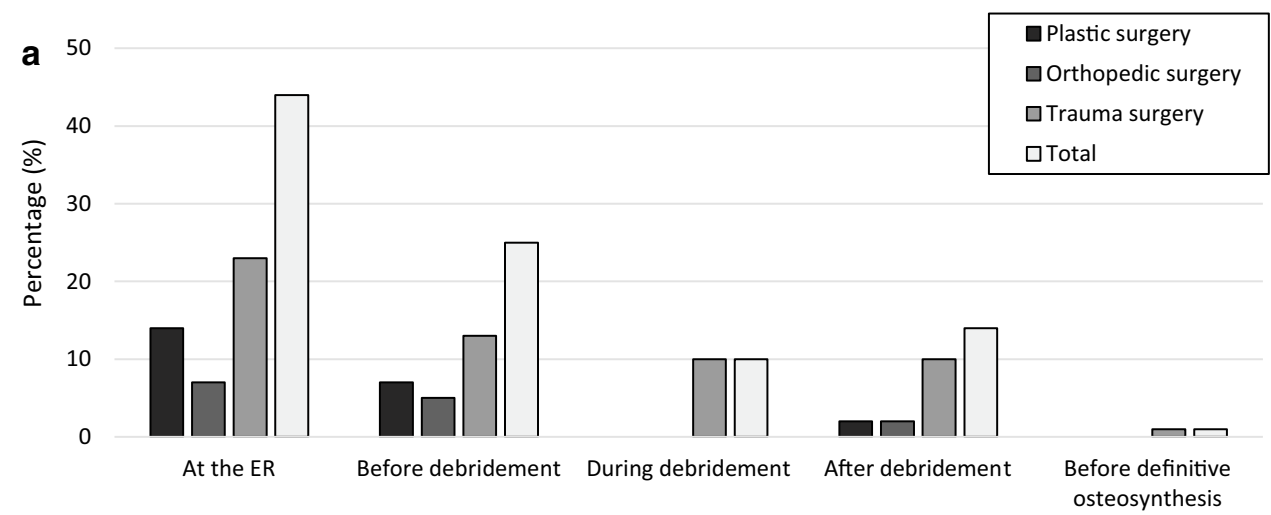

b
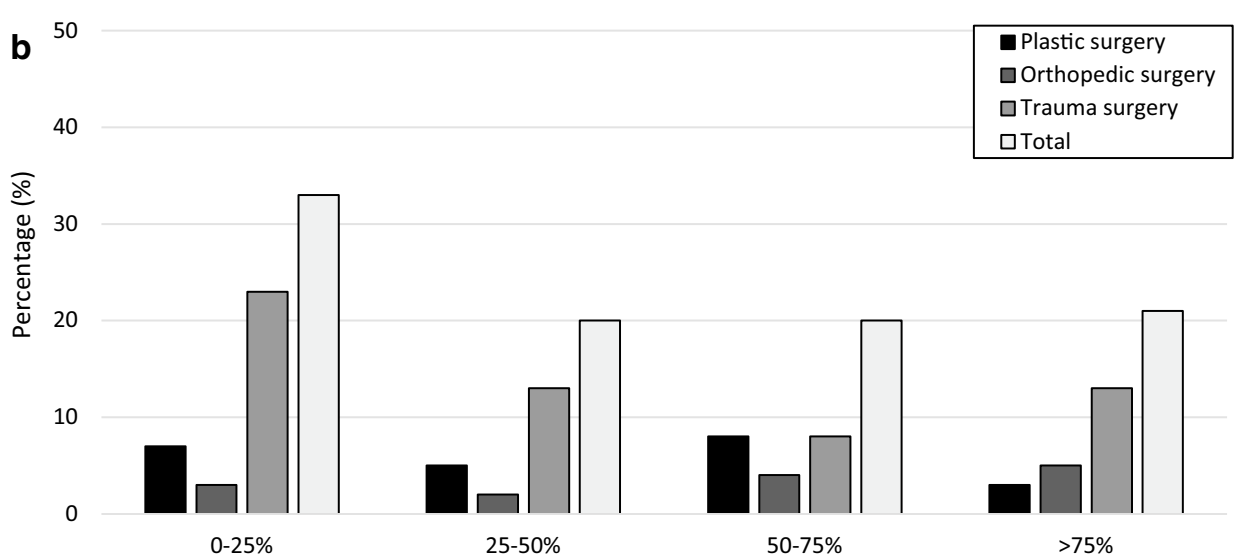
orthopedic and trauma surgeons have a target period of 14 days for soft-tissue coverage. Finally, four out of five surgeons agreed that Gustilo 3 fractures should be centralized.

In 2009, the BOAST 4 Standards were published which emphasized the importance of early transfer of patients with complex open lower limb fractures to a specialist centre [15]. In 2012, major trauma centres (MTC) and associated major trauma networks were created to improve patient transfer in the UK [9-11]. The major goal was reducing complications such as osteomyelitis by means of soft-tissue coverage within $72 \mathrm{~h}$ of injury.

There are three ED levels in The Netherlands, level 1 ED with the basic available care to level 3 ED with 24-h specialized care, 14 in total across the country. Several specialists are involved in treating open lower limb fractures: ED physicians, trauma surgeons, orthopedic surgeons, plastic surgeons, rehabilitation specialist, physiotherapists, and nurses specialized in wounds. ED physician informs the trauma or orthopedic surgeon about the arrival of complicated lower limb fracture. In general, either the trauma or orthopedic surgeon has the lead in the treatment and requests consultations of different specialists.

In the last decade, trauma systems have been established in several countries resulting in improved quality of care.
In Ohio, USA, the mortality of trauma patients decreased by $40 \%$ after the establishment of a major trauma network [7]. Studies in Canada reported a decrease of 24-29\% [4, 16]. Implementation of an inclusive trauma system in The Netherlands was associated with a substantial and significant risk reduction (16\%) of death [3]. However, a Dutch national guideline has only recently (2017) been developed specific for the management of severe open lower limb fractures.

Ali et al. reported the outcomes of the treatment of open lower limb fractures after the centre was established as an MTC and compared these to the period before the establishment. The time from injury to soft-tissue coverage fell from 6 to 3.5 days, the time from definitive fixation to soft-tissue coverage fell from 5.0 to 2.0 days, and the deep infection rate fell from 27 to $8 \%$ [9]. Morrison et al. reported a decrease in required surgeries for patients that were directly admitted to the MTC, and underwent surgery only in the MTC in the Standards era (2011) compared to the Guidelines era (2006-2009) [10]. Wordsworth et al. reported a successful limb reconstruction rate of $98.5 \%$ and a deep infection rate of 1 in 65 in another MTC [11]. In our cohort, most surgeons were in favour of centralizing Gustilo 3 fractures.

A significant number of Dutch surgeons-mostly orthopedic and trauma surgeons- had a long target period for
Fig. 2 When and by whom first debridement should be done in case of a lower limb Gustilo 3 fracture
Fig. 3 Target period for definitive skeletal stabilization when soft-tissue coverage is needed
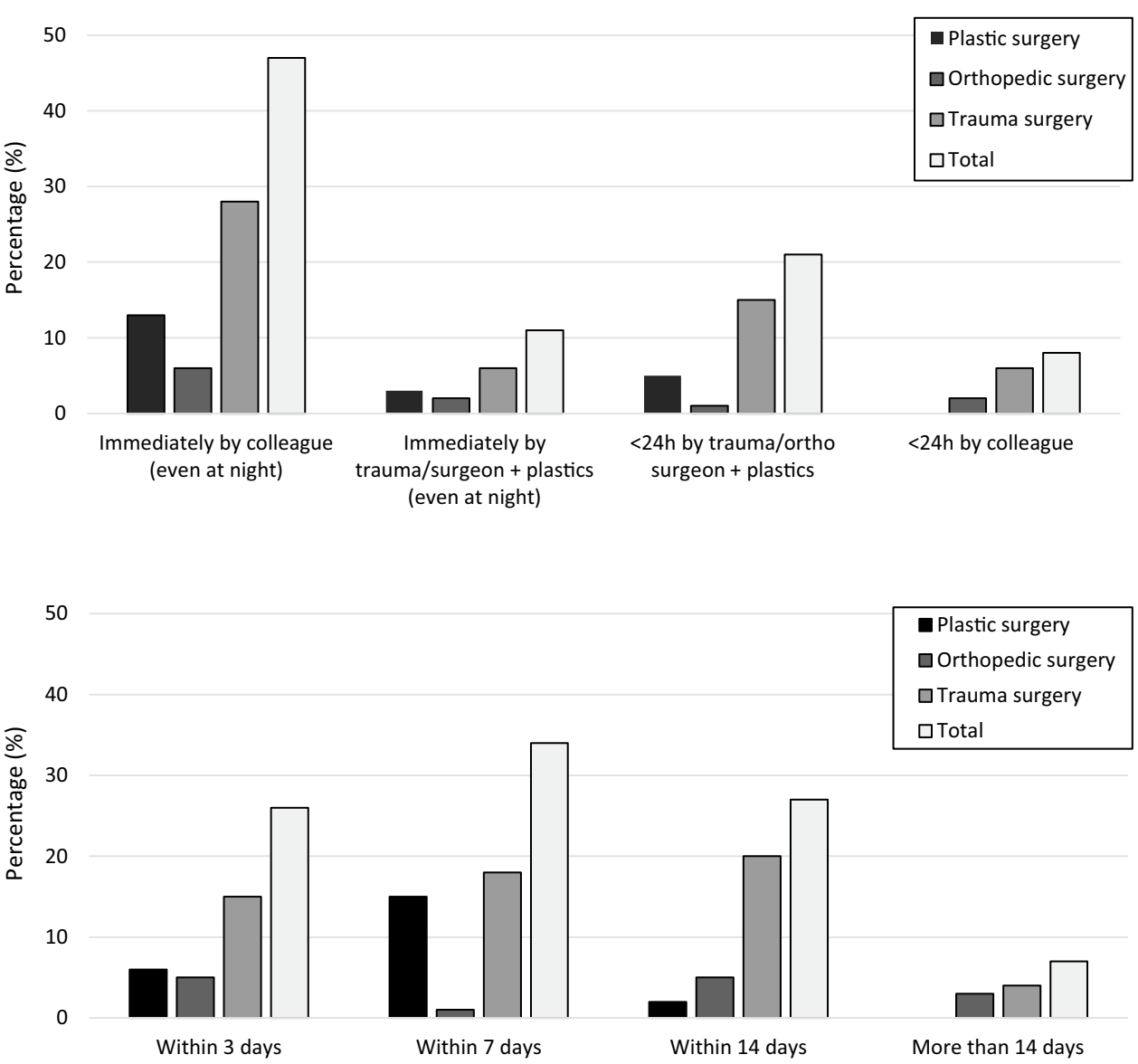
Fig. 4 Opinions about centralization of open lower limb fractures

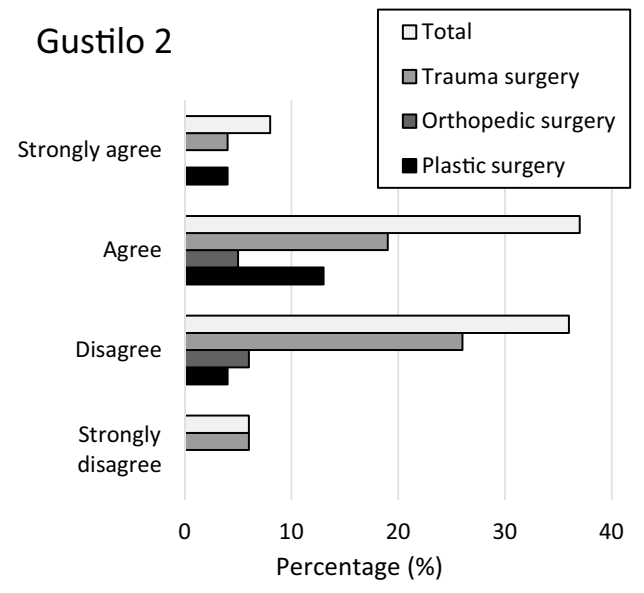

Gustilo 3

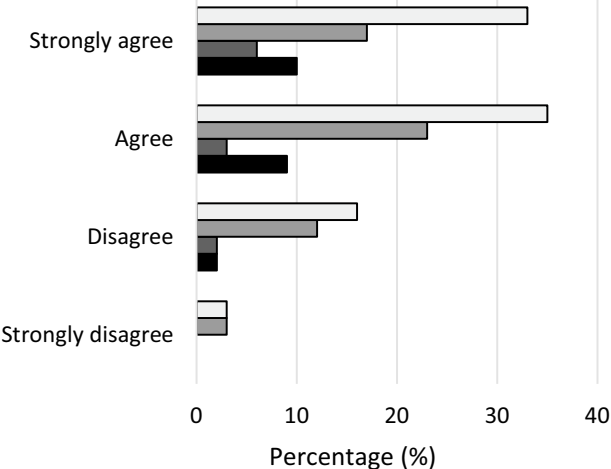

definitive skeletal stabilization if soft-tissue coverage is needed of more than 7 days. Exact rates are unknown, but it is estimated that significant number of these patients is not transferred quick enough to level I and II centres, with all essential specialists available 24/7, probably because of an initial underestimation of the injury severity. Most surgeons agreed that there should be a MDC in an early phase of treatment. Decreasing the treatment time in The Netherlands, by early transfer, a specialized multidisciplinary team, and a lower target period for soft-tissue coverage, might result in fewer required surgeries, higher limb reconstruction rate, and fewer complications.

The results should be interpreted in light of the strengths and limitations of the study. First, most responding surgeons worked in a hospital with a level I or II trauma level. Consequently, it is no surprise that these surgeons were agreeing on early transfer and centralization. Then again, many surgeons working in a rural hospital with a level III emergency department already do not treat these patients nowadays. Contrary to most other countries, both orthopedic and trauma surgeons treat bony injuries in The Netherlands. Second, some nuances are needed in generalizing these results. The answers on many of the questions about the current treatment depend on several factors, e.g., size of the wound, OR availability. Thus, surgeons opt for the best treatment for that patient, which means that some BOAST 4-related questions are hard to answer.

Even in a country like The Netherlands, where trauma care is well organized, the current treatment of complex open lower limb fractures in many hospitals is inadequate. Our results showed that The Netherlands should use their close network and infrastructure to aim to improve patient care and outcome for these patients. Moreover, the professionals from all disciplines seem to agree on steps to be taken such as centralization better interdisciplinary communication by defining teams and reduction of time between trauma and cover. An initial treatment by an adequate team within $24 \mathrm{~h}$, instead of soon after arrival, should contribute to better outcomes. The results of this study will help the implementation of the Dutch guideline for the management of open lower limb fractures.

\section{Conclusion}

This study clarified that the involved surgeons agree with the major components in managing the multidisciplinary therapy of open lower limb fractures. The importance of team work is essential and the Dutch surgeons agree on early transfer of the fractures to specialized trauma centres, and these are largely in accordance with the BOAST 4 standards.

This was the first step in implementing a new guideline. Our future aim is to compare the Dutch guideline with the original British guideline. Furthermore, we aim to assess the thoughts after implementing the Dutch guideline and compare those with the baseline results presented in this study. Eventually, we hope to get more insights on how to implement new medical guidelines in general for several European countries.

Author contributions Study design: KO, JMH, PZ, ETW, HRH, WAE, and HR. Data assembly: KO and HR. Data analysis: KO, JMH, PZ, and HR. Initial draft: KO, JMH, and HR. Final approval of manuscript: KO, JMH, PZ, ETW, HRH, WAE, and HR.

\section{Compliance with ethical standards}

Conflict of interest K. Oflazoglu, J.M. Hoogendoorn, P. van der Zwaal, E.T. Walbeehm, W.A. van Enst, H.R. Holtslag, D. Hofstee, P. Plantinga, M. Elzinga, and H. Rakhorst declare that they have no conflict of interest.

Research involving human participants and/or animals None.

Informed consent None.

Open Access This article is distributed under the terms of the Creative Commons Attribution 4.0 International License (http:// 
creativecommons.org/licenses/by/4.0/), which permits unrestricted use, distribution, and reproduction in any medium, provided you give appropriate credit to the original author(s) and the source, provide a link to the Creative Commons license, and indicate if changes were made.

\section{Appendix}

See Table 2.

Table 2 Results of the questionnaire about the current practice and therapy in The Netherlands

\begin{tabular}{|c|c|c|c|c|}
\hline Results questionnaire & Plastic surgery & Orthopedic surgery & Trauma surgery & Total \\
\hline \multicolumn{5}{|l|}{ Working specialist in center, $n(\%)$} \\
\hline General orthopedic surgeon & $19(83)$ & $9(69)$ & $50(89)$ & $78(85)$ \\
\hline Orthopedic surgeon + trauma degree & $20(87)$ & $13(100)$ & $32(57)$ & $65(71)$ \\
\hline General surgeon & $19(83)$ & $9(69)$ & $40(71)$ & $68(74)$ \\
\hline Trauma surgeon & $23(100)$ & $11(84)$ & $55(98)$ & $89(97)$ \\
\hline Plastic surgeon, no microsurgery & $6(26)$ & $3(23)$ & $16(29)$ & $25(27)$ \\
\hline Plastic surgeon, with microsurgery & $22(96)$ & $8(62)$ & $39(70)$ & $69(75)$ \\
\hline Rehabilitation specialist & $22(96)$ & $8(62)$ & $50(89)$ & $80(87)$ \\
\hline Emergency department physician & $21(91)$ & $10(77)$ & $48(86)$ & $79(86)$ \\
\hline \multicolumn{5}{|l|}{ Doctors in partnership, $n(\%)$} \\
\hline 1 & $2(8.7)$ & 0 & $1(1.8)$ & $3(3.3)$ \\
\hline 2 & $2(8.7)$ & $3(23)$ & $7(13)$ & $12(13)$ \\
\hline 3 & $9(39)$ & 0 & $7(13)$ & $13(17)$ \\
\hline 4 & $3(13)$ & $4(31)$ & $8(15)$ & $15(16)$ \\
\hline 5 & $3(13)$ & $1(7.7)$ & $10(18)$ & $14(15)$ \\
\hline 6 & $1(4.4)$ & $2(15)$ & $9(16)$ & $12(13)$ \\
\hline$>6$ & $3(13)$ & $3(23)$ & $14(25)$ & $20(22)$ \\
\hline \multicolumn{5}{|l|}{ Lower leg surgeries per year, $n(\%)$} \\
\hline$<5$ & $10(43)$ & $7(54)$ & $20(36)$ & $37(40)$ \\
\hline $5-10$ & $9(39)$ & $3(23)$ & $18(32)$ & $30(33)$ \\
\hline $10-15$ & $1(4.4)$ & $3(23)$ & $7(13)$ & $11(12)$ \\
\hline $15-20$ & $1(4.4)$ & 0 & $6(11)$ & $7(7.7)$ \\
\hline $20-25$ & 0 & 0 & $3(5.4)$ & $3(3.3)$ \\
\hline$>25$ & $2(8.7)$ & 0 & $2(3.6)$ & $4(4.4)$ \\
\hline \multicolumn{5}{|l|}{ Specialists in $\mathrm{MDC}^{\mathrm{a}}, n(\%)$} \\
\hline Trauma surgeon & $22(96)$ & $10(77)$ & $56(100)$ & $88(96)$ \\
\hline Orthopedic surgeon & $12(52)$ & $12(92)$ & $30(54)$ & $54(59)$ \\
\hline Plastic surgeon & $18(78)$ & $8(62)$ & $36(64)$ & $62(67)$ \\
\hline Microbiologist & $7(30)$ & $2(15)$ & $16(29)$ & $25(27)$ \\
\hline Rehabilitation specialist & $14(61)$ & $3(23)$ & $31(55)$ & $48(52)$ \\
\hline Radiologist & 0 & 0 & 0 & 0 \\
\hline \multicolumn{5}{|l|}{$\mathrm{MDC}^{\mathrm{a}}$ at the ED in case of Gustilo 2, $n(\%)$} \\
\hline $0-25 \%$ & $19(83)$ & $6(46)$ & $47(84)$ & $72(78)$ \\
\hline $25-50 \%$ & $2(8.7)$ & $3(23)$ & $2(3.6)$ & $7(7.6)$ \\
\hline $50-75 \%$ & $2(8.7)$ & $2(15)$ & $3(5.4)$ & $7(7.6)$ \\
\hline$>75 \%$ & 0 & $2(15)$ & $4(7.1)$ & $6(6.5)$ \\
\hline \multicolumn{5}{|l|}{$\mathrm{MDC}^{\mathrm{a}}$ at the ED in case of Gustilo 3, $n(\%)$} \\
\hline $0-25 \%$ & $7(30)$ & $3(23)$ & $22(39)$ & $32(34)$ \\
\hline $25-50 \%$ & $5(22)$ & $2(15)$ & $13(23)$ & $20(22)$ \\
\hline $50-75 \%$ & $8(35)$ & $3(23)$ & $8(14)$ & $13(21)$ \\
\hline$>75 \%$ & $3(13)$ & $5(38)$ & $13(23)$ & $21(23)$ \\
\hline \multicolumn{5}{|l|}{ Best moment for $\mathrm{MDC}^{\mathrm{a}}, n(\%)$} \\
\hline At the ER & $14(61)$ & $6(46)$ & $22(39)$ & $42(46)$ \\
\hline Before debridement & $7(30)$ & $5(38)$ & $13(23)$ & $25(27)$ \\
\hline During debridement & 0 & 0 & $10(18)$ & $10(11)$ \\
\hline After debridement & $2(8.7)$ & $2(15)$ & $10(18)$ & $14(15)$ \\
\hline Before definitive osteosynthesis & 0 & 0 & $1(1.8)$ & $1(1.1)$ \\
\hline
\end{tabular}


Table 2 (continued)

\begin{tabular}{|c|c|c|c|c|}
\hline Results questionnaire & Plastic surgery & Orthopedic surgery & Trauma surgery & Total \\
\hline Is everyone available for $\mathrm{MDC}^{\mathrm{a}}$ (even at night) & $19(83)$ & $9(69)$ & $32(57)$ & $60(65)$ \\
\hline \multicolumn{5}{|l|}{ Who decides amputation, $n(\%)$} \\
\hline $\mathrm{Me}$ & $2(8.7)$ & 0 & $7(13)$ & $9(10)$ \\
\hline Together with trauma & $21(91)$ & $7(54)$ & $45(80)$ & $73(79)$ \\
\hline Together with plastic & $4(17)$ & $9(69)$ & $24(43)$ & $37(40)$ \\
\hline Together with orthopedics & $4(17)$ & $5(38)$ & $5(8.9)$ & $14(15)$ \\
\hline \multicolumn{5}{|l|}{ Target period definitive osteosynthesis, $n(\%)$} \\
\hline$<3$ days & $12(52)$ & $3(23)$ & $17(30)$ & $32(35)$ \\
\hline$<7$ days & $11(48)$ & $3(23)$ & $19(34)$ & $33(36)$ \\
\hline$<14$ days & 0 & $7(54)$ & $20(36)$ & $27(29)$ \\
\hline \multicolumn{5}{|c|}{ Gustilo $\geq 2$; Target period definitive osteosynthesis, $n(\%)$} \\
\hline$<3$ days & $10(43)$ & $2(15)$ & $8(14)$ & $20(22)$ \\
\hline$<7$ days & $12(52)$ & $2(15)$ & $11(20)$ & $25(27)$ \\
\hline$<14$ days & $1(4.4)$ & $6(46)$ & $30(54)$ & $37(40)$ \\
\hline$>14$ days & 0 & $3(23)$ & $7(13)$ & $10(11)$ \\
\hline \multicolumn{5}{|c|}{ Gustilo $\geq 2+$ flap; Target period definitive osteosynthesis, $n(\%)$} \\
\hline$<3$ days & $6(26)$ & $5(38)$ & $15(27)$ & $26(28)$ \\
\hline$<7$ days & $15(65)$ & $1(7.7)$ & $17(30)$ & $33(36)$ \\
\hline$<14$ days & $2(8.7)$ & $4(31)$ & $20(36)$ & $26(28)$ \\
\hline$>14$ days & 0 & $3(23)$ & $4(7.1)$ & $7(7.7)$ \\
\hline \multicolumn{5}{|l|}{ Who will join definitive coverage, $n(\%)$} \\
\hline Trauma surgeon & $21(91)$ & $5(38)$ & $54(96)$ & $80(87)$ \\
\hline Orthopedic surgeon & $13(57)$ & $7(54)$ & $7(13)$ & $27(29)$ \\
\hline Plastic surgeon & $23(100)$ & $13(100)$ & $55(98)$ & $91(99)$ \\
\hline Microbiologist & $5(22)$ & 0 & $15(27)$ & $20(22)$ \\
\hline Rehabilitation specialist & $6(26)$ & $2(15)$ & $17(30)$ & $25(27)$ \\
\hline
\end{tabular}

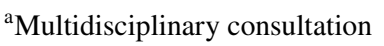

\section{References}

1. Jana Neto FC, de Paula Canal M, Alves BA, Ferreira PM, Ayres JC, Alves R. Analysis of the characteristics of patients with open tibial fractures of Gustilo and Anderson type III. Rev Bras Ortop. 2016;51(2):143-9.

2. Hoogendoorn JM, van der Werken C. Grade III open tibial fractures: functional outcome and quality of life in amputees versus patients with successful reconstruction. Injury. 2001;32(4):329-34.

3. Twijnstra MJ, Moons KG, Simmermacher RK, Leenen LP. Regional trauma system reduces mortality and changes admission rates: a before and after study. Ann Surg. 2010;251(2):339-43.

4. Tallon JM, Fell DB, Karim SA, Ackroydstolarz S, Petrie D. Influence of a province-wide trauma system on motor vehicle collision process of trauma care and mortality: a 10-year follow-up evaluation. Can J Surg. 2012;55(1):8-14.

5. Crandall ML, Esposito TJ, Reed RL, Gamelli RL, Luchette FA. Analysis of compliance and outcomes in a trauma system with a 2-h transfer rule. Arch Surg. 2010;145(12):1171-5.

6. Culica D, Aday LA, Rohrer JE. Regionalized trauma care system in Texas: implications for redesigning trauma systems. Med Sci Monit. 2007;13(5):SR9-18.

7. Claridge JA, Allen D, Patterson B, DeGrandis F, Emerman C, Bronson D, et al. Regional collaboration across hospital systems to develop and implement trauma protocols saves lives within 2 years. Surgery. 2013;154(4):875-82 (discussion 82-4).
8. Nanchahal JN, Khan S, Moran U, Barrett C, Sanderson S, Pallister F. I. Standards for the management of open fractures of the lower limb. London: Royal Society of Medicine Press; 2009. http://www.bapras.org.uk/professionals/clinical-guidance/openfractures-of-thelower-limb\#Full Guide.

9. Ali AM, McMaster JM, Noyes D, Brent AJ, Cogswell LK. Experience of managing open fractures of the lower limb at a major trauma centre. Ann R Coll Surg Engl. 2015;97(4):287-90.

10. Trickett RW, Rahman S, Page P, Pallister I. From guidelines to standards of care for open tibial fractures. Ann R Coll Surg Engl. 2015;97(6):469-75.

11. Wordsworth M, Lawton G, Nathwani D, Pearse M, Naique S, Dodds A, et al. Improving the care of patients with severe open fractures of the tibia: the effect of the introduction of Major Trauma Networks and national guidelines. Bone Joint J. 2016;98-B(3):420-4.

12. Court-Brown CM, Bugler KE, Clement ND, Duckworth AD, McQueen MM. The epidemiology of open fractures in adults. A 15-year review. Injury. 2012;43(6):891-7.

13. Gustilo RB, Anderson JT. Prevention of infection in the treatment of one thousand and twenty-five open fractures of long bones: retrospective and prospective analyses. J Bone Joint Surg Am. 1976;58(4):453-8.

14. Kommer GJ GR, Lemmens LC, Kooistra M, Deuning C. Beschikbaarheid, specialisatie en bereikbaarheid van Spoedeisende hulp in Nederland: Analyse gevoelige ziekenhuizen. RIVM Rapport 2015-0077. 2015. 
15. BOA/BAPRAS. BOAST 4: The management of severe open lower limb fractures. British Orthopaedic Association and British Association of Plastic, reconstructive and aesthetic surgeons standard for trauma. 2009.
16. Moore L, Hanley JA, Turgeon AF, Lavoie A. Evaluation of the long-term trend in mortality from injury in a mature inclusive trauma system. World J Surg. 2010;34(9):2069-75.

\section{Affiliations}

\section{K. Oflazoglu ${ }^{1}$ (D . J. M. Hoogendoorn ${ }^{2} \cdot$ P. van der Zwaal ${ }^{3} \cdot$ E. T. Walbeehm ${ }^{4} \cdot$ W. A. van Enst ${ }^{5} \cdot$ H. R. Holtslag ${ }^{6}$. D. Hofstee ${ }^{7} \cdot$ P. Plantinga ${ }^{8} \cdot$ M. Elzinga ${ }^{9} \cdot$ H. Rakhorst ${ }^{10}$}

J. M. Hoogendoorn

J.Hoogendoorn@haaglandenmc.nl

P. van der Zwaal

p.van.der.zwaal@haaglandenmc.nl

E. T. Walbeehm

erikwalbeehm@mac.com

W. A. van Enst

a.vanenst@ kennisinstituut.nl

H. R. Holtslag

h.r.holtslag@amc.uva.nl

D. Hofstee

d.j.hofstee@nwz.nl

P. Plantinga

pplantinga@rijnstate.nl

M. Elzinga

matthijs.elzinga@gmail.com

\section{H. Rakhorst}

h.rahkhorst@mst.nl

1 Research fellow Orthopedic Hand Service, Orthopedic Surgery, Harvard Medical School, Massachusetts General Hospital, Yawkey Center, 55 Fruit Street, Boston,

MA 02114, USA
2 Department of Trauma Surgery, Haaglanden Medical Center, The Hague, The Netherlands

3 Department of Orthopedic and Trauma Surgery, Haaglanden Medisch Centrum, The Hague, The Netherlands

4 Department of Plastic and Reconstructive Surgery, Radboud University Medical Centre, Nijmegen, The Netherlands

5 Kennisinstituut van de Federatie Medisch Specialisten, Utrecht, The Netherlands

6 Department of Rehabilitation Medicine, Academic Medical Centre, Amsterdam, The Netherlands

7 Department of Orthopedic Surgery, Noordwest Ziekenhuis Groep, Alkmaar, The Netherlands

8 Emergency Department, Rijnstate Hospital, Arnhem, The Netherlands

9 Department of Trauma Surgery, VU Medical Centre, Amsterdam, The Netherlands

10 Department of Plastic and Reconstructive Surgery, Medisch Spectrum Twente, Enschede, The Netherlands 